\title{
DESCONSTRUINDO PRECONCEITOS, REDEFININDO CONCEITOS: TRABALHADORES DE SAÚDE EM ANGOLA
}

\author{
DECONSTRUCTING PREJUDICES, REDEFINING \\ CONCEPTS: ANGOLAN HEALTH WORKERS
}

\section{DECONSTRUYENDO PREJUICIOS, REDEFINIENDO CONCEPTOS: TRABAJADORES DE SALUD DE ANGOLA}

\author{
Euclides Nenga Manuel Sacomboio ${ }^{1}$
}

Como citar este artigo: Sacomboio ENM. Desconstruindo preconceitos, redefinindo conceitos: trabalhadores de saúde em Angola. Rev baiana enferm. 2019;33:e34496.

Dados do país (Angola) apontam que o Sistema Nacional de Saúde (SNS) e a rede sanitária compreendem 2.681 unidades sanitárias, nomeadamente 15 hospitais nacionais, 25 hospitais provinciais, 45 hospitais gerais, 170 hospitais municipais, 442 centros de saúde, 67 centros materno-infantis, 1.880 postos de saúde e 37 outras infraestruturas de saúde. Estas unidades contam com uma força de trabalho de 69.816 trabalhadores, sendo 3.500 médicos angolanos, 35.458 profissionais de enfermagem (enfermeiros, técnicos e auxiliares) e 8.078 técnicos de diagnóstico e terapêutica (biomédicos, odontologistas, radiologistas, cardiopneumologistas, fisioterapeutas, nutricionistas e outros profissionais de saúde) ${ }^{(1-2)}$. Esse número de profissionais de saúde é responsável por atender uma população de cerca de 30 milhões de habitantes em uma extensão territorial de $1.247 \mathrm{mil} \mathrm{km}$.

Trata-se de pessoas que não são super-heróis. São apenas pessoas que fazem aquilo pelo qual foram formadas para fazer. Fala-se de pessoas de Angola que, em tempos de guerra ${ }^{(3)}$, enquanto todo mundo escondia-se de bombas, granadas, morteiros e abus em trincheiras e outros lugares seguros, estavam em lugar estranho chamado hospital, ao ar livre, expostas a todos os tipos de bombardeamentos possíveis, tanto por parte das tropas da oposição quanto das tropas do governo, porque sua missão é salvar vidas.

Fala-se de médicos, enfermeiros, técnicos de diagnóstico e terapêutica, pessoas que receberam e atenderam, em tempos de guerra fria em Angola, mutilados, baleados, esquartejados, corpos e pedaços de corpos de pessoas vivas e mortas; pessoas que viram seu local de trabalho lotado de gente ferida de forma grave ou moderada, ouviram gritos de dor, de luto, de angústia e de desespero. Mesmo diante desse quadro, tentavam manter-se firmes e fortes, fazendo o seu trabalho, que é proporcionar alento aos pacientes, atendendo todos e tudo sem ao menos perguntar se eram do lado do governo ou da oposição, se eram crentes ou ateus e se eram ricos ou pobres. Afinal, a guerra era entre irmãos, filhos da mesma terra.

Enfermeiro. Doutor em Ciências da Saúde. Coordenador do Departamento de Investigação Científica e Pós-Graduação do Instituto Superior de Ciências da Universidade Agostinho Neto. Luanda, Angola. euclissacomboio@hotmail.com. http://orcid.org/0000-0002-234|-9133 
Em contraste com a guerra, esses profissionais estavam vestidos de branco, o branco da paz e da harmonia, o branco da pureza. Por isso, não estavam em nenhum dos lados da guerra. O único lado que conheciam e conhecem é que a guerra era entre humanos e que a dignidade humana começa no nascimento e não termina com a morte. Em lugar das armas dos soldados, usadas para matar e ferir seus opositores, esses profissionais usavam suas ferramentas para salvar vidas. Seus instrumentos eram a vontade, a coragem, a empatia, a solidariedade. Em suas mãos, tinham o estetoscópio, o termómetro, o esfigmomanômetro, o glucómetro, a balança, a seringa, a agulha e todos os outros instrumentos para salvar vidas. Embora não estando em nenhum dos lados da guerra, centenas deles foram mortos por arma de fogo, por bombardeamento nos seus locais de trabalho, soterrados em escombros, quer por tropas do governo, quer por tropas da oposição, mas, ainda assim, não abandonaram seus postos de trabalho em tempo de guerra.

Além da guerra, outros problemas que assolavam esse país, entre eles a desnutrição, a malária, a cólera, o sarampo, a poliomielite, o tétano, as hepatites e muitas outras doenças ${ }^{(1)}$ dependiam totalmente do atendimento desses profissionais. Contudo, foram os soldados do governo e da oposição que receberam honras por seus feitos, medalhas por sua bravura, reconhecimento por suas estratégias e bens materiais, como carros, casas e outros, além de obterem um status social melhor que ninguém. Os profissionais de saúde não tiveram seus méritos reconhecidos; passaram em branco. Isso em um contexto de 27 anos de guerra, que teve início em 1975 e finalizou em $2002^{(4)}$.

Com a paz, a incidência de pacientes vítimas da guerra diminuiu. Entretanto, o cenário epidemiológico do país, conforme citado $^{(1)}$, continuou o mesmo, acrescendo-se, em outubro de 2004 , o reaparecimento de uma doença quase que extinta no mundo moderno. Depois de tanto sofrimento que seu povo passou, surgiu a epidemia de febre hemorrágica provocada pelo vírus de Marburg, que matou mais de duas centenas de angolanos. Embora tenham ocorrido mortes também nas províncias de Malange, Cabinda, Luanda, Cuanza Norte, Cuanza Sul e Zaire, a doença afetou principalmente a província do Uíge. Para fazer frente a essa doença, foram mobilizados meios técnicos e humanos de várias organizações nacionais e internacionais ${ }^{(5)}$.

A maioria das pessoas mobilizadas, se não todas, eram profissionais de saúde que abandonaram suas famílias, suas casas e suas cidades para prestar assistência aos seus concidadãos afetados pela doença. Muitos desses profissionais acabaram morrendo. Segundo relatório do Ministério da Saúde de Angola, até março de 2005, cerca de 227 pessoas morreram de Marburg na província do Uíge. Dessas, 23 eram profissionais de saúde, sendo 16 enfermeiros, 2 médicos e 5 terapeutas ${ }^{(5)}$ que prestavam assistência aos pacientes e contaminaram-se com o vírus. Isso dá em torno de 10\% do total de mortes pela doença. Em 2005, conseguiu-se controlar o Marburg em Angola. Mais uma vez, a mídia reconheceu os esforços do governo, das entidades internacionais e de outros. Entretanto, os profissionais de branco não receberam méritos. As famílias dos que morreram por seus grandes feitos não foram amparadas, seus salários e subsídios não foram pagos e muitos dos familiares que dependiam desses profissionais até hoje sequer recebem uma pensão.

Em dezembro de 2015, uma nova história épica começa: era o surto de febre amarela, acompanhada de malária ${ }^{(6)}$ e associado a uma crise econômica sem precedentes em Angola. O país registrou um dos maiores surtos de febre amarela urbana da África, com taxas de morbi-mortalidade assustadoras. Os hospitais estavam lotados e as condições técnicas, materiais, estruturais e funcionais das unidades de saúde não ofereciam condições para se prestar assistência de qualidade aos pacientes. Mais uma vez, os profissionais de branco precisaram entrar em cena.

A Organização Mundial da Saúde reporta que a epidemia fez mais de 400 mortes ${ }^{(6)}$. Os hospitais careciam de tudo, desde profissionais, a equipamentos, materiais, como luvas e máscaras, medicamentos, camas, reagentes para exames e todos os outros insumos necessários para a assistência dos pacientes. Nessa conjuntura, os profissionais de branco estavam lá, trabalhando duro, passando no mínimo 
8 horas e, às vezes, ultrapassando 24 horas de trabalho no hospital, expostos a uma variedade de pacientes com doenças infectocontagiosas em camas, macas e no chão, distribuídos em salas e corredores lotados. Um profissional atendia no mínimo 30 pacientes por dia, chegando a atender 100 pacientes por dia, o que acontece até hoje. Ainda assim, esses profissionais tentam, com toda sua energia, prestar cuidados de saúde e outros, como informação sobre o quadro de saúde do paciente aos familiares e amigos.

Essa classe, até um tempo, foi conhecida como trabalhadores não produtivos, porque o estado não lucra com sua atividade. Contudo, os pacientes atendidos são a força produtiva do país; os que fazem o lucro do país. Neste editorial, faz-se menção a profissionais que têm os salários mais empobrecidos ou empobrecedores. Por exemplo, no topo da carreira, o enfermeiro e outros profissionais denominados técnicos de diagnóstico e terapêutica ganham hoje cerca de 380 mil kwanzas como salário base, e o médico aufere, no máximo, 405 mil kwanzas $^{(7)}$ (equivalentes, respectivamente, a R $\$ 3.000,00$ e R $\$ 3.300,00$ no Brasil), enquanto técnicos e auxiliares recebem salários que chegam a ser duas ou três vezes menores que esses. Para compensar essa falta de dinheiro, a maioria desses profissionais tem mais de um emprego. Por isso, vivem trabalhando, o que compromete o cuidado com a sua própria saúde, principalmente diante do fato de Angola estar entre os países mais caros para se viver no mundo.

Devido às precárias condições de trabalho, esses profissionais estão constantemente expostos a riscos de quedas, lesões por esforços repetitivos (LER), distúrbios osteomusculares relacionados ao trabalho (DORT) e outras doenças decorrentes das atividades físicas ou mentais, fruto da exposição contínua a agentes infeciosos, além de estresses e pressões decorrentes do trabalho. Na maioria das vezes, trabalham sem os adequados equipamentos de proteção individual e/ou colectiva e passam muito tempo em posições inadequadas, ao prestar atendimento quase sempre a pacientes acamados, em macas e muitas vezes no chão. Esses profissionais trabalham entre 8 e 12 horas contínuas, até que outro colega os renda. Caso isso não aconteça, fazem outro turno, porque não podem abandonar o local de trabalho.

Além disso, esses profissionais vivem em condições precárias, pois se alimentam mal, algumas vezes comem alimentos sem teor nutricional adequado, não têm lugares adequados para preparar suas medicações e fazer os seus registros. Após uma jornada pesada de trabalho, cochilam em chão frio e contaminado do hospital ou em macas e camas dos pacientes, já que não há lugar para que possam descansar na hora da vela (período em que alguns colegas cobrem outros para proporcionar um tempo de descanso). Quando adoecem, são vítimas da própria precariedade do sistema de saúde em que trabalham e que os fez adoecer. Por isso, e por viverem vestidos de branco (sem reconhecimento), os chamamos profissionais em branco; quando morrem, passam em branco (sem serem lembrados).

\section{Referências}

1. República de Angola. Ministério da Saúde. Plano Nacional de Desenvolvimento Sanitário 2012-2025. Mais e Melhor Saúde. Volume 1 [Internet]. Luanda; ago 2012 [cited 2019 Oct 20]. Available from: http//www.minsa. gov.ao.downloads/PNDS_2012_2025_VOL_1.pdf

2. Profissionais da Saúde vão ser enquadrados em setembro. Nova Gazeta. Noticas de Angola [Internet]. 2019 ago 22 [cited 2019 Oct 28]. Available from: https://www.noticiasdeangola.co.ao/profissionais-dasaude-vao-serenquadrados-em-setembro/

3. Polgreen L. Angolans Come Home to 'Negative Peace' [Internet]. The New York Times. 2003 Jul 30 [cited 2019 Oct 21 . Available from: https://www.nytimes.com/2003/07/30/world/angolans-come-home-to-negative-peace.html

4. Angola e os caminhos para a paz efectiva [Internet]. ANGOP - Agência Angola Press. 2018 abr 2 [cited 2019 Oct 26]. Available from: https://www.angop.ao/angola/pt_pt/noticias/politica/2018/2/13/Angola-caminhos-para-pazefectiva,3968b99e-799a-4a69-83ff-b1ab6dabf0b2.html 
5. Anúncio do fim do vírus de Marburg marca noticiário social [Internet]. ANGOP - Agência Angola Press. 2005 nov 12 [cited 2019 Oct 18]. Available from: http://www.angop.ao/angola/pt_pt/noticias/saude/2007/11/50/ Anuncio-fim-virus-Marburg-marca-noticiario-social,eaef049e-fbf2-40c0-a0f6-561bf96e6272.html

6. OMS declara fim da epidemia de febre-amarela em Angola e República Democrática do Congo [Internet]. Rádio Observador. 2017 fev 15 [cited 2019 Oct 18]. Available from: https://observador.pt/2017/02/15/ oms-declara-fim-da-epidemia-de-febre-amarela-em-angola-e-republica-democratica-do-congo/

7. Kitari M. Diplomatas, docentes e médicos com actualização salarial [Internet]. O País. 2019 jan [cited 2019 Nov 1]. Available from: https://opais.co.ao/index.php/2018/12/28/diplomatas-docentes-e-medicos-com-actualizacao-salarial/

Recebido: 8 de novembro de 2019

Aprovado: 8 de novembro de 2019

Publicado: 16 de março de 2020

A Revista Baiana de Enfermagem utiliza a Licença Creative Commons - Atribuição-NãoComercial 4.0 Internacional.

https://creativecommons.org/licenses/by-nc/4.0/

Este artigo é de acesso aberto distribuído sob os termos da Licença Creative Commons (CC BY-NC).

Esta licença permite que outros remixem, adaptem e criem a partir do seu trabalho para fins não comerciais. Embora os novos trabalhos tenham de lhe atribuir o devido crédito e não possam ser usados para fins comerciais, os usuários não têm de licenciar esses trabalhos derivados sob os mesmos termos. 